\title{
An Abnormal Triglyceride-rich Lipoprotein Containing Excess Sialylated Apolipoprotein C-III
}

\author{
G. Holdsworth, J. Stocks, P. Dodson, and D. J. Galton, Diabetes and Lipid \\ Research Laboratory, Department of Medicine, St. Bartholomew's Hospital, \\ London E.C.1, England
}

\begin{abstract}
AB S T R A C T An abnormal triglyceride-rich lipoprotein has been isolated from some patients with chronic renal failure or severe hypertriglyceridemia. The abnormal lipoprotein was characterized by an increased content of apolipoprotein (apo) C-III-2 $(57.5 \%$ of total apo C-III peptides compared with $35.5 \%$ for controls, $P<0.001)$ as characterized by isoelectric focusing and scanning densitometry. As determined by a substrate competition assay, the abnormal lipoprotein was a less efficient substrate for purified bovine milk lipoprotein lipase than control lipoproteins. Neuraminidase digestion of abnormal or control lipoprotein resulted in a reduction of the apo C-III-2 band with a corresponding increase in the region of apo C-III-0, which suggests that the increased content of apo C-III-2 in the abnormal is due to excessive sialylation of the C-III peptide. Limited incubation of the abnormal lipoproteins with neuraminidase caused a partial loss of sialic acid and resulted in a triglyceride-rich lipoprotein with a normal C-III-2:C-III-1 ratio. This preparation displayed normal substrate interaction with lipoprotein lipase. Three severely hypertriglyceridemic patients with the abnormal lipoprotein showed a marked reduction in serum triglyceride concentration, which is associated with a reversion to a normal $\mathrm{C}$-peptide profile after dietary therapy. The results suggest that the extent of sialylation of the apo C-III peptide carried on triglyceride-rich lipoproteins may be critical for their interaction with lipoprotein lipase.
\end{abstract}

\section{INTRODUCTION}

The triglyceride-rich lipoproteins are cleared from the circulation by the action of lipoprotein lipase (E.C.

Dr. Holdsworth's present address is Department of Pharmacology and Cell Biophysics, University of Cincinnati Medical Center, Cincinnati, OH 45267.

Received for publication 22 May 1981 and in revised form 3 October 1981.
3.1.1.34) (1). This enzyme is secreted from parenchymal cells such as adipoctyes and acts at the capillary endothelium to hydrolyze the triglyceride moiety of chylomicrons and very low density lipoproteins (VLDL) ${ }^{1}$ with some accompanying hydrolysis of phospholipid (2). In conditions where lipoprotein lipase is absent or greatly reduced in peripheral tissues (type 1 hyperlipidemia and insulin-deficient states), there is an associated gross hypertriglyceridemia $(3,4)$.

The enzyme requires the presence of an activator peptide, apolipoprotein (apo) C-II, carried on VLDL and chylomicrons for maximal triglyceride hydrolysis to occur. The importance of this peptide in vivo is shown by the impaired degradation of triglyceriderich lipoproteins in patients with familial or acquired apo C-II deficiency, which results in a severe hypertriglyceridemia $(5,6)$. This hypertriglyceridemia exists despite adequate levels of lipoprotein lipase activity in postheparin plasma or adipose tissue. Infusions of plasma as a source of apo C-II produces a rapid clearance of the hypertriglyceridaemia in both inherited and acquired types of disease.

There have been reports that other surface peptides on triglyceride-rich lipoproteins may modify the activity of lipoprotein lipase. For example apo C-III has been shown to inhibit the activity of the enzyme in vitro (7). However, this peptide displays at least three isomorphic forms, which differ according to their sialic acid content. Thus apo C-III-0, C-III-1, and C-III-2 contain 0,1 , and 2 molecules of sialic acid, respectively, per molecule of peptide (8).

Alterations in the relative proportions of the apo CIII isoforms have been previously observed under various dietary and metabolic states. Thus, in streptozotocin-induced diabetic rats fed a high sucrose diet, there was an increased content of apo C-III-2 and re-

${ }^{1}$ Abbreviations used in this paper: Apo, apolipoprotein; VLDL, very low density lipoprotein. 
duced content of apo C-III-0 in their triglyceride-rich lipoproteins (9). In rats fed a high carbohydrate diet, the relative proportions of apo C-III-0 increased, whereas apo C-III-3 fell in plasma VLDL (10). And in humans fed a high-carbohydrate fat-free diet for $7 \mathrm{~d}$ there was an increase of apo C-III-0 relative to the other C-peptides on VLDL (11).

We have previously reported in preliminary form a variant triglyceride-rich lipoprotein from two hypertriglyceridemic subjects that contained an excess proportion of apo C-III-2, as characterized by polyacrylamide gel electrophoresis (12). This was associated with an impaired interaction of the abnormal lipoprotein with lipoprotein lipase. In the present paper we provide a more detailed peptide analysis of the abnormal lipoprotein obtained from two patient groups and demonstrate that the impaired interaction of the abnormal lipoprotein with lipoprotein lipase depends critically on the extent of sialylation of the apo C-III peptide and in particular on the proportions of C-III2 to C-III-1.

\section{METHODS}

Patients. Triglyceride-rich lipoproteins were obtained from fresh fasting sera of patients with type IV or type $V$ hyperlipidemia or from normolipidemic subjects during routine lipid screening. Patients with both primary and secondary hypertriglyceridemia (to obesity and alcohol excess) were included. Some patients had already started treatment by dietary therapy.

Further blood samples were obtained from patients with chronic renal failure (three dialyzed and one nondialyzed) attending the Renal Unit of St. Bartholomew's Hospital, and from subjects attending the Diabetic and Lipid Clinics. Analysis of the C-peptide content of triglyceride-rich lipoproteins by polyacrylamide gel electrophoresis identified those patients whose triglyceride-rich lipoproteins contained a relative excess of apo C-III-2 peptide as previously described (12). Table I presents the individual clinical details of these patients. Four hypertriglyceridemic patients with the abnormal lipoprotein were found in $2 \mathrm{yr}$ of screening $\sim 200$ patients with hypertriglyceridemia in our Lipid Clinic. As can be seen from the significance tests in Table I, these abnormalities do not fall within the right-hand tail of the distribution curve of control hypertriglyceridemics.

Isolation of triglyceride-rich lipoproteins. The triglyceride-rich lipoprotein fraction $(d<1.006)$ was prepared by ultracentrifugation in $\mathrm{NaCl} 0.195 \mathrm{mmol} /$ liter containing EDTA $0.27 \mu \mathrm{mol} /$ liter for $18 \mathrm{~h}$ at $35,000 \mathrm{rpm}$ in an MSE $8 \times 50-\mathrm{ml}$ angle-head rotor (MSE Scientific Instruments, Manor Royal, Crawley, Sussex, England). The chylomicronVLDL fraction was removed with a pipette and purified by ultracentrifugation in the same medium.

An alternative method for the initial isolation of triglyceride-rich lipoproteins used the density gradient centrifugation method (13). The serum was adjusted to a density of 1.22 by the addition of $0.32 \mathrm{~g}$ of $\mathrm{NaBr} / \mathrm{ml}$ of serum. This mixture was then layered below a continuous $\mathrm{NaCl} / \mathrm{NaBr}$ gradient of density range 1.006-1.2, and centrifuged for 2 $h$ at $28,000 \mathrm{rpm}$ in an MSE $3 \times 25-\mathrm{ml}$ swing-out rotor. The lipoprotein layer at the surface of the gradient was collected with a pipette and purified by recentrifugation in isotonic $\mathrm{NaCl} /$ EDTA $(0.195 \mathrm{mmol} / \mathrm{liter}$ and $0.27 \mu \mathrm{mol} / \mathrm{liter})$ as described above. In some experiments, chylomicrons were prepared by ultracentrifugation of serum for $1 \mathrm{~h}$ at $25,000 \mathrm{rpm}$ in an angle-head rotor, followed by recentrifugation in $\mathrm{NaCl} /$ EDTA as described above.

\section{Analysis of apoproteins}

Polyacrylamide gel electrophoresis. The method used for the analysis of the $\mathrm{C}$ peptides has been described in full detail by Kane (14).

Isoelectric focusing. The lipoproteins were delipidated with ethanol:ether as described by Scanu and Edelstein (15). The apoproteins were dissolved in freshly prepared urea 6 $\mathrm{mol} /$ liter and then subjected to flat-bed isoelectric focusing at pH 4-6. Details of the procedure have been given previously (16). In brief, $100-200 \mu \mathrm{g}$ of protein was applied to polyacrylamide gels with the following composition: $6 \mathrm{~mol} /$ liter urea, $51 \mathrm{~g} /$ liter acrylamide, $1.01 \mathrm{mmol} /$ liter glycerol, $0.73 \mathrm{mmol} /$ liter ammonium persulphate, $0.33 \mathrm{ml} /$ liter ampholine, pH 4-6 (Bio-Rad Laboratories, Richmond, CA).

TABLE I

Clinical Details and Peptide Composition of Subjects with an Abnormal Triglyceride-rich Lipoprotein

\begin{tabular}{|c|c|c|c|c|c|c|c|c|c|c|}
\hline \multirow[b]{2}{*}{ Patient } & \multirow[b]{2}{*}{ Age } & \multirow[b]{2}{*}{ Sex } & \multirow[b]{2}{*}{ Weight } & \multirow{2}{*}{$\begin{array}{c}\text { Serum } \\
\text { cholesterol }\end{array}$} & \multirow[b]{2}{*}{$\begin{array}{l}\text { Serum } \\
\text { triglyceride }\end{array}$} & \multicolumn{3}{|c|}{$\begin{array}{l}\text { Percentage of peptide composition } \\
\text { of apo C-III }\end{array}$} & \multirow{2}{*}{$\frac{\text { C-III-2 }}{\text { C-III-1 }}$} & \multirow[b]{2}{*}{ Diagnosis } \\
\hline & & & & & & C-III-0 & C-III-1 & C-III-2 & & \\
\hline & $y r$ & & $\mathrm{~kg}$ & \multicolumn{2}{|c|}{ mmol/liter } & & & & & \\
\hline 1 & 40 & $\mathbf{M}$ & 81 & 23.4 & 90 & 6 & 40 & 53 & 1.32 & Hypertriglyceridemia \\
\hline 2 & 51 & $\mathbf{M}$ & 66 & 11 & 24 & 4.5 & 31 & 65 & 2.1 & Hypertriglyceridemia \\
\hline 3 & 48 & $\mathbf{M}$ & 68 & 44 & 95 & 5.5 & 40.6 & 53.6 & 1.32 & Hypertriglyceridemia \\
\hline 4 & 35 & $\mathbf{M}$ & 67 & 64 & 122 & 14 & 28 & 58 & 2.07 & Hypertriglyceridemia \\
\hline 5 & 28 & $\mathbf{M}$ & 55.6 & 2.9 & 2.8 & 4.2 & 33.9 & 64.2 & 1.88 & Chronic renal failure \\
\hline 6 & 52 & $\mathbf{M}$ & 80 & 2.1 & 2.1 & 5.8 & 36.4 & 58.3 & 1.60 & Chronic renal failure \\
\hline 7 & 32 & $\mathbf{M}$ & 80 & 3.5 & 2.9 & 13.3 & 30.4 & 56.6 & 1.84 & Chronic renal failure \\
\hline 8 & 51 & $\mathbf{M}$ & 66.8 & 5.3 & 2.6 & 7.5 & 41.1 & 51.8 & 1.27 & Chronic renal failure \\
\hline
\end{tabular}


Electrophoresis was carried out at $600 \mathrm{~V}$ and $50 \mathrm{~mA}$ for 30 min and at $800 \mathrm{~V}$ and $10 \mathrm{~mA}$ for a further $2.5 \mathrm{~h}$. The gels were stained with Page Blue 83 .

Scanning densitometry. Both polyacrylamide and isoelectric focusing gels were scanned in a Vitatron MPS densitometer with a 550-nm filter. The relative quantities of apoproteins were calculated by triangulation of peak areas and expressed as a percentage of total C-III. Calibration curves with purified apoprotein C-III-1 showed good linearity between peak areas and quantity of apoprotein applied to gel. However, results are not expressed as mass of apoprotein present but as relative proportions.

Neuraminidase incubation. This was carried out after mixing equal volumes of triglyceride-rich lipoprotein sam-

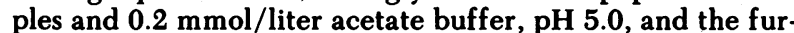
ther addition of $50 \mu \mathrm{l}$ of $0.5 \mathrm{mg} / \mathrm{ml}$ neuraminidase (C. perfringens, Sigma Chemical Co., St. Louis, MO) in acetate buffer, and incubation at $37^{\circ} \mathrm{C}$ for $1 \mathrm{~h}$. Controls were incubated in acetate buffer alone.

Partial desialylation of the lipoprotein was achieved by incubation with the enzyme as above for only $5 \mathrm{~min}$. Enzyme activity was stopped by the addition of solid bromide (to a concentration of $3.1 \mathrm{mmol} /$ liter), followed by storage in an ice bath at $4^{\circ} \mathrm{C}$. The incubation mixtures were then introduced under the density gradient described above, and centrifuged for $2 \mathrm{~h}$ in the swing-out rotor. After this and subsequent washing and centrifuging steps, the neuraminidasetreated and control lipoproteins were concentrated by ultrafiltration with an Amicon PM10 membrane (Amicon Corp., Scientific Systems Div., Lexington, MA). All serum lipoprotein and digests were assayed for cholesterol and triglyceride according to standard autoanalytical procedures; namely, the Technicon Instruments Corp. (Tarrytown, NY) method N.77, with Liebermann-Burchard's reagent for cholesterol, and Cramp and Robertson's (17) fluorometric method for triglyceride.

Interaction of lipoproteins with lipoprotein lipase. The efficiency with which the abnormal triglyceride-rich lipoproteins acted as a substrate for lipoprotein lipase was assessed by incubation of the patients' or controls' triglyceriderich lipoproteins with a constant activity of isolated and partially purified bovine milk lipoprotein lipase. A substrate competition assay was used, which employed a synthetic radiochemical triglyceride emulsion prepared as previously described (18). Volumes $(250 \mu \mathrm{l})$ of this substrate were incubated with $10 \mu$ l of the purified bovine milk lipoprotein lipase preparation, $100 \mu \mathrm{l}$ of fresh human fasting serum to ensure complete activation of the enzyme, and various volumes (up to $140 \mu \mathrm{l}$ ) of patients' or controls' triglyceride-rich lipoprotein. After incubation at $37^{\circ} \mathrm{C}$ for $1 \mathrm{~h}, 200 \mu \mathrm{l}$ of the mixture was extracted in a Belfrage-Vaughan partition system (19). $1 \mathrm{ml}$ of the upper phase was counted in a Packard Instrument Co. (Downers Grove, IL) liquid scintillation counter (model 2420).

Addition of the triglyceride-rich lipoproteins to the assay system resulted in a dose-dependent reduction in the amount of labeled free fatty acid formed, compared with assays containing no added lipoprotein. A comparison of these reductions between equivalent triglyceride concentrations of patients' or controls' lipoproteins gave a measure of the efficiency of substrate interaction of lipoprotein with the enzyme. The synthetic substrate was fully activated by normal serum. During the assay, however, we could not exclude the possibility of direct transfer of C-III-2 from abnormal lipoprotein to substrate. This would be expected to minimize the differences that were actually observed.

The control substrate competition curves were performed with triglyceride-rich lipoproteins obtained from hypertriglyceridemic patients with a wide range of serum triglyceride concentrations (4-160 mmol/liter). In other experiments, separate chylomicron and VLDL fractions were isolated from the serum of patients with severe type $V$ hyperlipidemia. The different sizes of these particles were checked by electron microscopy as previously described (16). The two lipoprotein fractions, with a normal apoprotein composition, displayed closely similar substrate competition curves (Fig. 1). This indicates that lipoprotein particle size is probably not an important factor in the substrate competition assay with triglyceride emulsion.

\section{RESULTS}

Apoprotein composition. Scans of representative isoelectric focusing gels of abnormal and control triglyceride-rich lipoproteins are shown in Fig. 2. From such scans the percentage of peptide composition of the abnormal lipoprotein from the two patient groups (severe hypertriglyceridemia and chronic renal failure) can be calculated and is presented in Table II. The hypertriglyceridemic control group is not well matched for age with the experimental groups, but there is no evidence that apoprotein composition alters by decades. The abnormal lipoproteins had a marked increase in the proportion of apo C-III-2 compared with control lipoproteins, with a corresponding decline in apo C-III-1 and

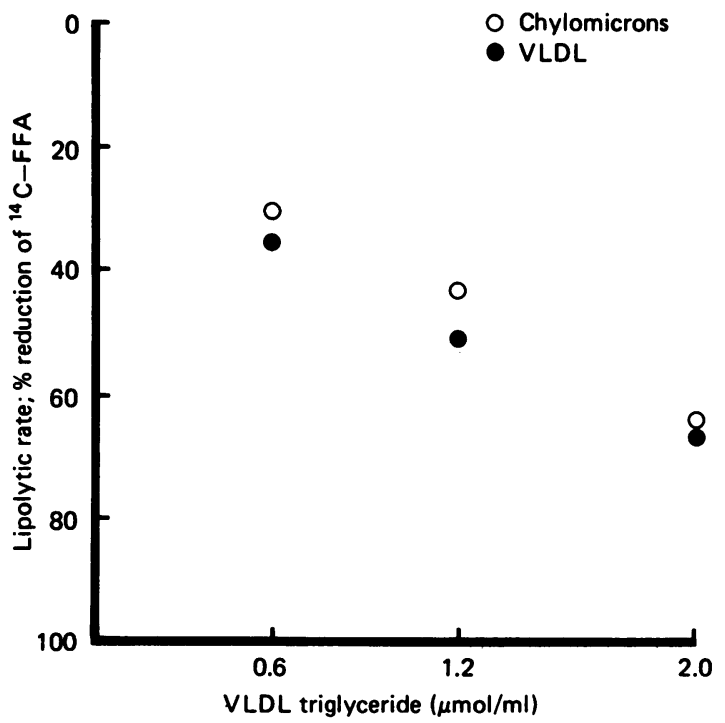

FIgURE 1 Interaction of chylomicrons and VLDL with purified bovine lipoprotein lipase. Chylomicrons and VLDL were prepared from sera of two subjects with type $V$ hyperlipidemia. The mean particle diameters as determined by electron microscopy were $104 \mathrm{~nm}$ for chylomicrons and $45 \mathrm{~nm}$ for VLDL. The ability of both lipoproteins to act as substrates for lipoprotein lipase was assessed in a substrate competition assay as described in Methods. Points are means of two patients measured in duplicate. 


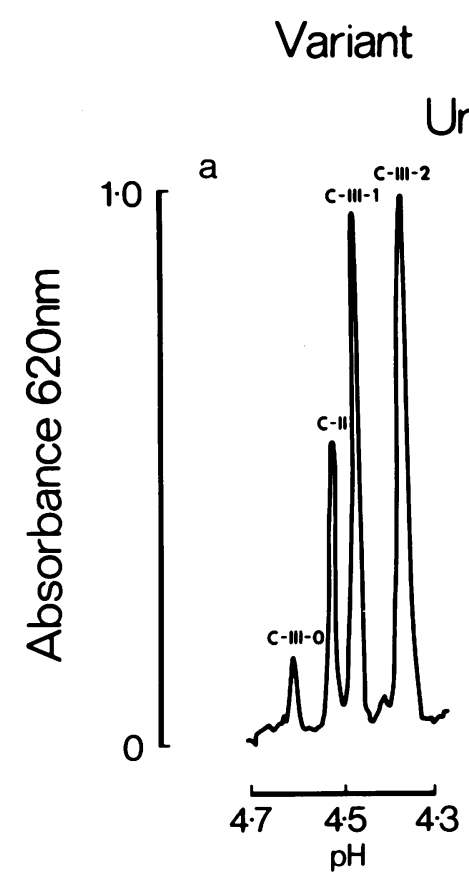

Untreated

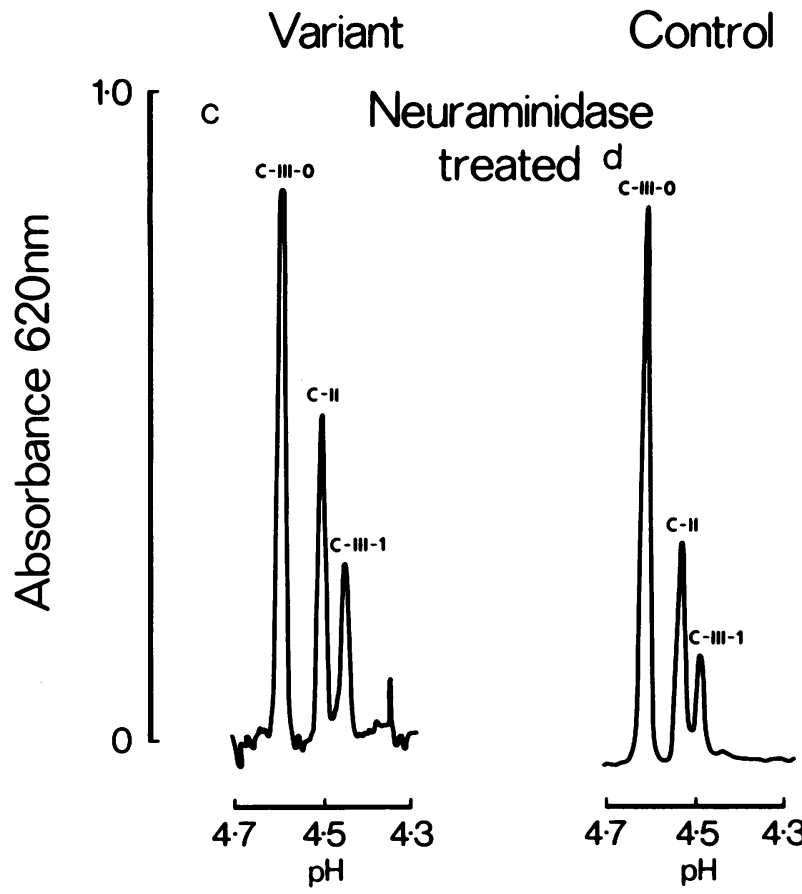

FIgURE 2 Isoelectric focusing of the $\mathrm{C}$ peptides of variant and control triglyceride-rich lipoproteins. Peptide analysis of the $C$ peptides of variant and control triglyceride-rich lipoproteins were carried out by isoelectric focusing in the pH range 4-6, as described in Methods. Densitometric scans of the stained bands were obtained with a Vitatron MPS spectrophotometer. (a) Hypertriglyceridemic variant, (b) control, (c) hypertriglyceridemic variant after neuraminidase digestion, (d) control after identical neuraminidase digestion. apo C-III-0. There was no difference in apo C-II content. There is little difference in the C-peptide composition between the abnormal lipoprotein from either renal or nonrenal sources, but both are markedly different from control VLDL and chylomicrons. The mean level of plasma triglyceride in the control group of Table II is lower than the mean of the hypertriglyceridemic subjects with the abnormal lipoprotein. One of the controls (and we have observed two other patients) had plasma triglycerides $>35 \mathrm{mmol} /$ liter and their percentage of composition of C-III-1 and C-III-2 was similar to normolipemic controls. It is therefore unlikely that the peptide abnormality results from hypertriglyceridemia per se.

The apo $\mathrm{E}$ content of the abnormal lipoprotein was estimated by polyacrylamide gel electrophoresis (which does not separate the $\mathrm{E}$ isoforms) and the percentage of composition was not significantly different from control lipoprotein. Treatment with neuraminidase before peptide analysis results in a decrease of the apo C-III-2 band from both variant and control gels, with a corresponding increase in the staining density of the apo C-III-0 region (Fig. 2c and d).

Substrate efficiency of the abnormal lipoprotein. The interaction of the abnormal lipoprotein with purified bovine milk lipoprotein lipase has been studied in a substrate competition assay. This was used because of lack of sensitivity in other methods to measure fatty acid release from lipoproteins. Fig. 3 presents the reduction of the ${ }^{14} \mathrm{C}$-labeled free fatty acid released by hydrolysis of a labeled triglyceride emulsion on addition to the incubation system of equal amounts of VLDL-triglyceride from control or variant sources. The labeled triglyceride emulsion provided a more effective substrate for the enzyme in mixtures containing the variant lipoprotein than in mixtures with control lipoprotein. The enzyme does not appear to discriminate between labeled triglyceride emulsion and control lipoprotein. Thus, at a 1:1 mixture of triglyceride emulsion and control lipoprotein $(1.2 \mu \mathrm{mol} / \mathrm{ml})$, there is a reduction of $47.6 \pm 1.6 \%$ $(n=14)$ in labeled free fatty acid formation (at $50 \%$ substrate dilution). The reduction in labeled free fatty acid formation at $50 \%$ substrate dilution for the abnormal lipoprotein was $30.3 \pm 3.7 \%$ ( $n=9$; of eight subjects studied), significantly less than in controls $(P<0.02$ by unpaired Student's $t$ test).

Modification of C-III-2 content. Limited incubation of the abnormal lipoproteins with neuraminidase produced lipoproteins with a normal C-III-2:C-III-1 ratio. These modified lipoproteins behaved like control lipoproteins in the substrate competition assay (Fig. 4). When all the apo C-III-2 was removed, however, the particle appeared to become a less efficient substrate for lipoprotein lipase. The extent to which the proportions of apo C-III peptides of triglyceride-rich lipoproteins are critical for enzyme-lipoprotein interaction can be judged 
TABLE II

Clinical Details and Peptide Composition of Triglyceride-rich Lipoproteins from Patient Groups

\begin{tabular}{|c|c|c|c|c|c|c|c|c|c|c|}
\hline \multirow[b]{2}{*}{ Patient groups } & \multirow[b]{2}{*}{ Age } & \multirow[b]{2}{*}{ Sex } & \multirow[b]{2}{*}{ Weight } & \multirow[b]{2}{*}{$\begin{array}{c}\text { Serum } \\
\text { cholesterol }\end{array}$} & \multirow[b]{2}{*}{$\begin{array}{l}\text { Serum } \\
\text { triglyceride }\end{array}$} & \multicolumn{5}{|c|}{ Percentage of peptide composition of apo C-III } \\
\hline & & & & & & C-III-0 & C-III-1 & C-III-2 & $\frac{\text { C-III-2 }}{\text { C-III-1 }}$ & $\frac{\text { C-II }}{\text { C-III }}$ \\
\hline & $y r$ & & $k g$ & \multicolumn{2}{|c|}{ mmol/liter } & & & & & \\
\hline $\begin{array}{l}\text { Normolipemic } \\
\text { Controls }(n=6)\end{array}$ & $47.8 \pm 9.9$ & $3 \mathrm{M}, 3 \mathrm{~F}$ & - & $6.2 \pm 0.60$ & $1.40 \pm 0.58$ & $7.5 \pm 5.4$ & $57 \pm 4.3$ & $35.3 \pm 6.5$ & $0.72 \pm .32$ & $0.29 \pm 0.097$ \\
\hline $\begin{array}{l}\text { Hypertriglyceridemic } \\
\text { controls }(n=9)\end{array}$ & $54.7 \pm 12$ & $9 \mathrm{M}$ & $78.4 \pm 15.7$ & $\begin{array}{c}8.76 \pm 5.0 \\
\text { range } \\
2.2-18.5\end{array}$ & $\begin{array}{c}18.1 \pm 23.8 \\
\text { range } \\
1.75-74\end{array}$ & $8.3 \pm 3.3$ & $56.1 \pm 8.3$ & $35.5 \pm 10.6$ & $0.66 \pm 0.28$ & $0.23 \pm 0.04$ \\
\hline $\begin{array}{l}\text { Hypertriglyceridemic } \\
\text { variants }(n=4)\end{array}$ & $43.5^{*} \pm 7.5$ & $4 \mathrm{M}$ & $70.6 \pm 7.0$ & $\begin{array}{c}35.6^{*} \pm 23 \\
\text { range } \\
11-64\end{array}$ & $\begin{array}{c}82.8 \ddagger \pm 43 \\
\text { range } \\
24-122\end{array}$ & $7.5 \pm 4.4$ & $358 \pm 6.5$ & $57.58 \pm 5.4$ & $1.7^{71} \pm 0.43$ & $0.22 \pm 0.06$ \\
\hline $\begin{array}{l}\text { Patients with chronic } \\
\text { renal failure ( } n= \\
\text { 4) }\end{array}$ & $41 \pm 13$ & $4 \mathrm{M}$ & $70 \pm 10$ & $3.4 \pm 1.3$ & $2.6 \pm 0.55$ & $7.7 \pm 4.1$ & $35.4^{\prime \prime} \pm 4.3$ & $57.7^{\prime \prime} \pm 4.7$ & $1.65^{\prime \prime} \pm 0.28$ & $0.18 \pm 0.02$ \\
\hline
\end{tabular}

The peptide analysis of triglyceride-rich lipoproteins was performed as in methods. Results expressed as percentage of total peptide present (means \pm SD). Significance of differences were calculated by unpaired Student's $t$ test.

$P<0.05$ vs. control.

$\ddagger P<0.02$ vs. control.

$\S P<0.001$ vs. control.

I $P<0.01$ vs. control.

from Fig. 5. This correlates the proportions of the Cpeptides on lipoproteins with their substrate efficiency at $50 \%$ substrate dilution. The percentage content of apo

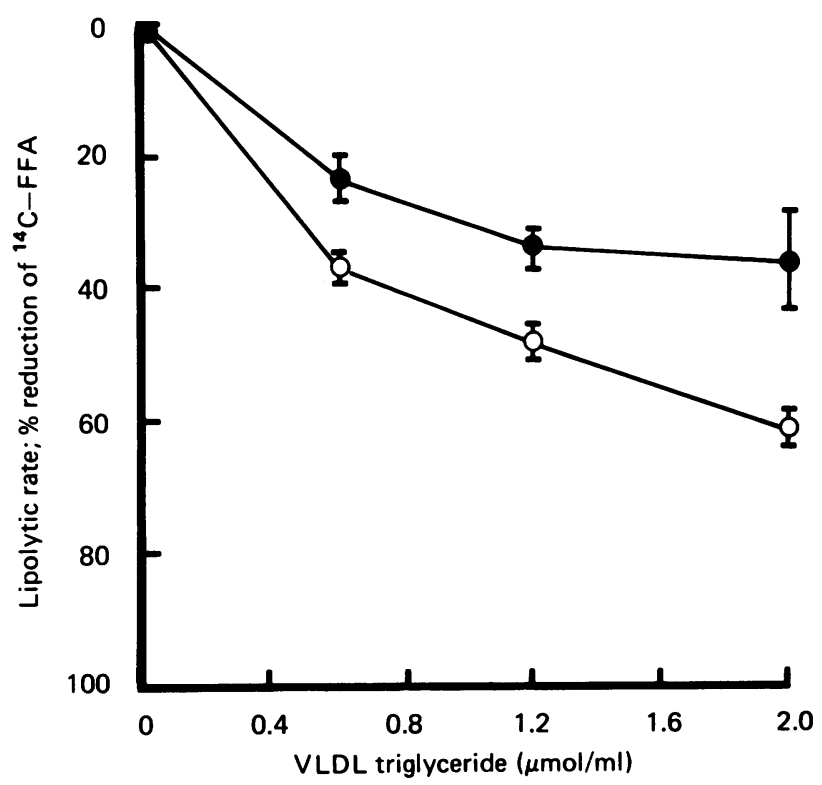

Figure 3 Interaction of variant and control triglyceriderich lipoproteins with purified bovine milk lipoprotein lipase. The ability of variant or control lipoprotein to act as substrate for purified bovine milk lipoprotein lipase was assessed in a substrate competition assasy described in Methods. Points are means \pm SEM of variant $(n=5)(0)$ and of control hypertriglyceridemic VLDL $(n=14)(0)$.
C-III-2 and C-III-1 showed strong and opposite correlations with the degree of hydrolysis by lipoprotein lipase but no correlation was observed with apo C-III-0.

Reversibility of the C-III-2 excess in vivo. The abnormal lipoproteins of three severely hypertriglyceridemic diabetic patients were restudied after their serum triglyceride concentrations had been reduced by dietary therapy. The C-peptide composition of the variant lipoprotein reverted towards the normal pattern and their reaction with lipoprotein lipase also improved, which shows that this is a reversible phenomenon, (Table III).

\section{DISCUSSION}

The composition of the C-peptides of human triglyceride-rich lipoproteins, first described in detail by Shore and Shore (20) and by Kane (14), appears to be similar to the proportions found in most hypertriglyceridemic subjects (21). In this paper, however, we describe an abnormal triglyceride-rich lipoprotein from two sources of patients (chronic renal failure and severe hypertriglyceridemia) that appears to contain excess apo C-III-2. This was identified by two different electrophoretic systems (acrylamide gel and isoelectric focusing) and the isoelectric point of the densely staining band of the variant is similar to that of control apo C-III-2. The disappearance of this band in gels obtained from the abnormal and control lipoproteins after digestion with neuraminidase, with the concomitant increase in staining in the region of apo C-III-0, also suggests a common identity of apo C-III-2 be- 


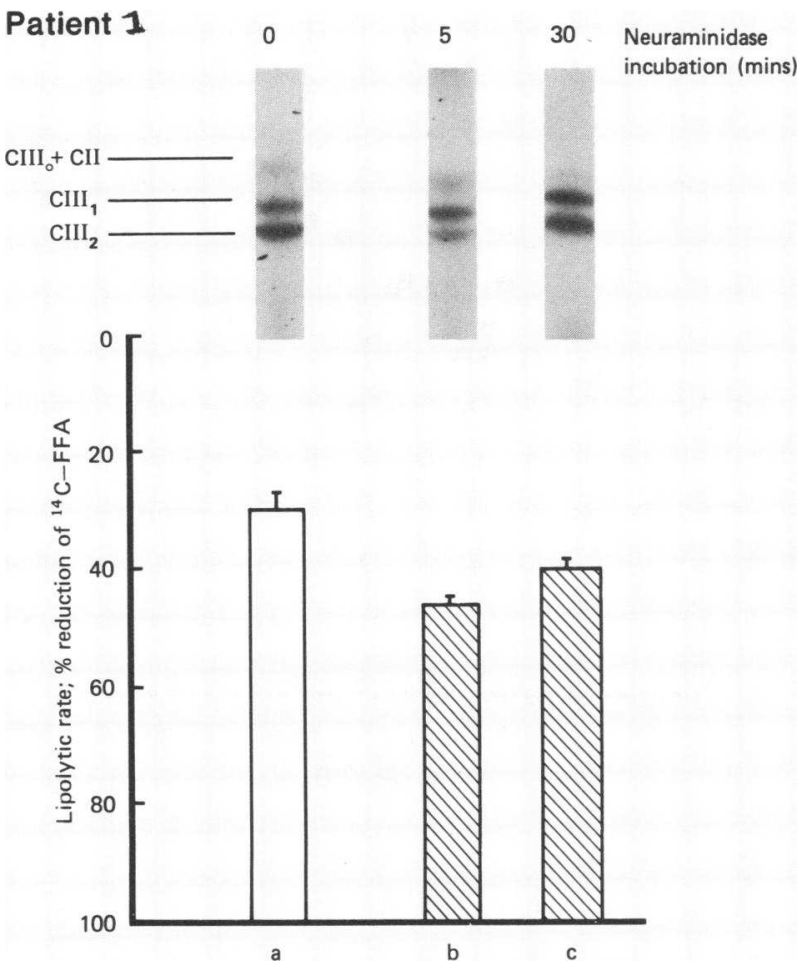

Figure 4 Partial digestion of variant lipoprotein with neuraminidase and their interaction with lipoprotein lipase. Samples of variant triglyceride-rich lipoproteins were incubated with a final concentration of $0.025 \mathrm{ng} / \mathrm{ml}$ neuraminidase in $0.1 \mathrm{mmol} /$ liter sodium acetate buffer, $\mathrm{pH}$ 5.0. Incubations were stopped at 5 and $30 \mathrm{~min}$, as described in the text, followed by separation of triglyceride-rich lipoprotein digests on a $\mathrm{NaBr}$ gradient (see Methods). The triglyceride concentrations of the lipoproteins and digests were analyzed by routine autoanalytical methods, and their $\mathrm{C}$ polypeptide profiles were analyzed using polyacrylamide gel electrophoresis in urea, $6 \mathrm{mmol} /$ liter. Patient $1:$ (a) control, incubated in buffer alone; (b) 5 min neuraminidase; (c) 30 min neuraminidase. The histogram associated with each gel gives the percentage of substrate competition of each sample or digest in the substrate competition assay at $50 \%$ substrate dilution. Bars represent standard deviations of duplicates from two experiments $(n=4)$. Patient 2: a, b, and c are as above for patient 1 . Results are means of triplicates of one experiment except in column (b) where $n=1$. C-III-2/C-III-1 ratios la:1.5, 1b:0.58, lc:0.1; 2a:1.4, 2b:0.66, 2c:0.21.

tween variant and control. This densely staining band in the variant is unlikely to be due to a contaminant.

The latter experiments also suggest that excess sialylation of the C-III peptide is responsible for the abnormality. The physiological mechanisms governing the extent of sialylation of apo C-III are poorly understood. The changes we observed could be due to increased sialylation reactions during synthesis of the Cpeptides or impaired desialylation during their catabolism. Different mechanisms could be operating to produce increased sialylation of apo C-III in different patient groups. Sialylation of apo C-III peptides occur in the Golgi body of rat liver and the extent of sialylation increases with the residence time of the nascent VLDL particle in this organelle (22). If there is delay in the transit of VLDL through the Golgi body in our patients with severe hypertriglyceridemia, this may account for the increased sialylation of their CIII peptides. Very little is known concerning the catabolism of human apo C-III, but this may occur partly in the kidney and may be altered in severe renal disease.

There are other examples where excess sialylation of a protein occurs and alters its functional properties. For example, in patients with severe liver disease there is excess sialylation of fibrinogen on the $\gamma$-chains, and this renders it a less efficient substrate for thrombin, consequently prolonging the thrombin time (23).

The increased apo C-III-2 content of the abnormal lipoprotein is unlikely to be due to the hypertriglyceridemia per se as our control hypertriglyceridemic group did not show a similar abnormality. Whatever the cause of the increased apo C-III-2 content of the variant lipoproteins, it was associated with impaired substrate interaction with lipoprotein lipase in vitro. Where reversion to a normal apoprotein composition occurred after dietary therapy, there was an improvement in the lipoprotein-enzyme interaction, which suggest that the impaired substrate efficiency of the particle with lipoprotein lipase may be a contributing factor to the etiology of the hypertriglyceridemia. Excess sialylation is unlikely to be a major factor, however, since the abnormal pattern was observed in two patient groups with widely differing mean plasma triglycerides (82 and $2.6 \mathrm{mmol} /$ liter, respectively). Thus, hypertriglyceridemia can occur without the CIII abnormality and the C-III abnormality can occur without severe hypertriglyceridemia. The development of hypertriglyceridemia may be the resultant of many factors, of which excess sialylation of apo C-III may be just one. On its own it may impair triglyceride clearance in vivo but not enough to produce hypertriglyceridemia. However, in association with increased hepatic production of triglyceride-rich lipoproteins, hypertriglyceridemia may develop. When the variant lipoprotein was treated with neuraminidase to produce a normal C-III-2:C-III-1 ratio, the substrate behavior of the modified lipoprotein was normal. However, when the apo C-III-2 content is further reduced by prolonged incubation with neuraminidase, the particle becomes a less efficient substrate for the enzyme, which suggests that some apo C-III-2 is required for optimal enzyme-substrate interaction.

We have previously reported variant lipoproteins associated with hypertriglyceridemia displaying im- 

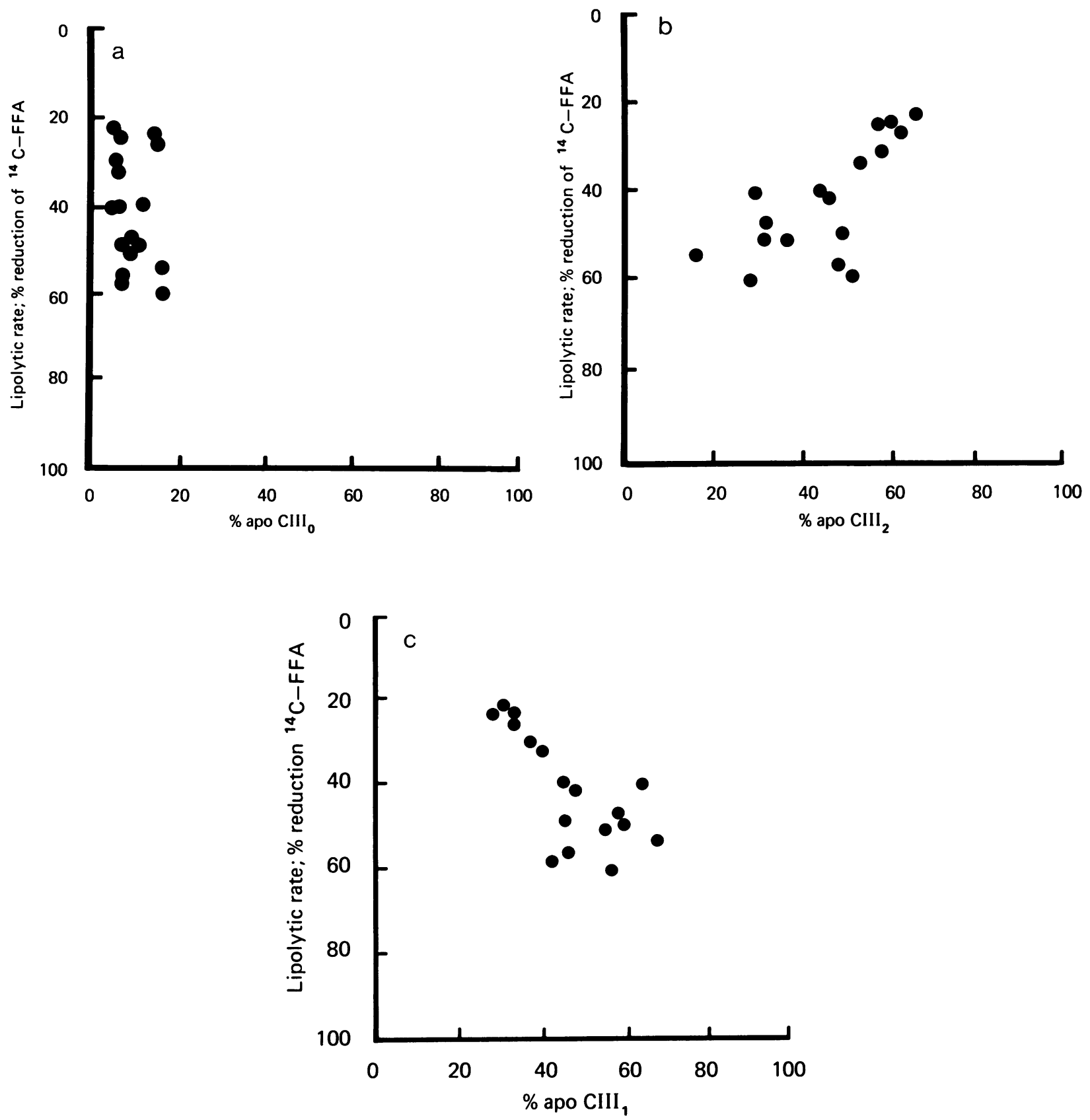

Figure 5 Correlations of the percentage compositions of the apo C-III peptides carried by variant and control triglyceride-rich lipoproteins with the percentage substrate competition at $50 \%$ substrate dilution. (See legend to Fig. 2 and Methods). (a) apo C-III-O; (b) apo C-III-2, $r=0.73, P<0.001$; (c) apo C-III-1, $r=0.72, P<0.01$.

paired interaction with lipoprotein lipase. These include a variant containing a marked reduction in apoprotein C-II (6) and a variant containing a marked increase in apo C-II (16). These studies, together with the results reported here, suggest that an alteration in the proportion of C-peptides carried on triglyceriderich lipoproteins may impair optimal interaction with lipoprotein lipase. Furthermore, the fact that the proportion of apo C-III-1 correlates positively, and apo C-III-2 negatively, with enzyme-substrate interaction 
TABLE III

Effects of Therapy on the Peptide Composition and Substrate Efficiency of the Variant Lipoprotein

\begin{tabular}{|c|c|c|c|c|c|c|c|}
\hline \multirow[b]{2}{*}{ Hypertriglyceridemic variants } & \multirow[b]{2}{*}{$\begin{array}{c}\text { Serum } \\
\text { triglyceride }\end{array}$} & \multirow[b]{2}{*}{$\begin{array}{c}\text { Serum } \\
\text { cholesterol }\end{array}$} & \multicolumn{4}{|c|}{ Percentage of peptide composition of apo C-III } & \multirow{2}{*}{$\begin{array}{l}\text { Substrate competition at } 50 \% \\
\text { substrate dilution (percentage } \\
\text { of initial values) }\end{array}$} \\
\hline & & & C-III-0 & C-III-1 & C-III-2 & $\frac{\text { C-III-2 }}{\text { C-III-1 }}$ & \\
\hline \multicolumn{8}{|c|}{$\mathrm{mmol} / \mathrm{liter}$} \\
\hline Before therapy $(n=3)$ & $70 \pm 40$ & $26.1 \pm 16.7$ & $5.33 \pm 0.76$ & $37.33 \pm 5.5$ & $57.33 \pm 6.65$ & $1.58 \pm 0.44$ & $72.8 \pm 7.4$ \\
\hline After therapy $(n=3)$ & $3.68 \pm 1.3$ & $7.7 \pm 1.5$ & $7.4 \pm 6.1$ & $51.0 \pm 5.6$ & $40.3 \pm 6.4$ & $0.8 \pm 0.2$ & $49 \pm 7.1$ \\
\hline
\end{tabular}

Peptide analysis and substrate efficiency of lipoprotein was measured as described in Methods.

Results are means \pm SD.

suggests that the covalent linkage of the second sialic acid residue to the apo C-III peptide may be critical for optimal hydrolysis of triglyceride-rich lipoprotein by the enzyme.

\section{ACKNOWLEDGMENTS}

We should like to thank Dr. A. R. Limbrick, University College of London, for the electron micrographs.

We are grateful for financial support from the Area Health Authority (T) (to Dr. Stocks) and the Joint Research Board of St. Bartholomew's Hospital (to Dr. Holdsworth).

\section{REFERENCES}

1. Robinson, D. S. 1970. The function of plasma triglycerides in fatty acid transport. Compr. Biochem. 18:

2. Scow, R. O., and T. Egelrud. 1976. Hydrolysis of chylomicron phosphatidylcholine in vitro by lipoprotein lipase, phospholipase $A_{2}$, and phospholipase C. Biochim. Biophys. Acta. 431: 538-549.

3. Harlan, W. R., S. Preston, P. S. Winesett, and A. J. Wasserman. 1967. Tissue lipoprotein lipase in normal individuals and in individuals with exogenous hypertriglyceridemia and the relationship of this enzyme to the assimilation of fat. J. Clin. Invest. 46: 239-247.

4. Durrington, P., J. E. MacIver, G. Holdsworth, and D. J. Galton. 1981. Severe hypertriglyceridaemia associated with pancytopenia and lipoprotein lipase deficiency. Ann. Intern. Med. 94: 211-212.

5. Breckenridge, W. C., A. Little, G. Steiner, and M. Poapst. 1978. Hypertriglyceridaemia associated with deficiency of apolipoprotein C-II. N. Engl. J. Med. 298: 1265-1273.

6. Reckless, J. P. D., J. Stocks, G. Holdsworth, D. J. Galton, A. J. Suggett, and K. W. Walton. 1979. Hypertriglyceridaemia and acquired deficiency of apolipoprotein C-II. Clin. Sci. (Oxf.). 57: 13P.

7. Brown, W. V., and M. L. Baginsky. 1972. Inhibition of lipoprotein lipase by an apoprotein of human very low density lipoprotein. Biophys. Biochem. Res. Commun. 46: 375-382.

8. Vaith, P., G. Assman, and G. Uhlenbruck. 1978. Characterization of the oligosaccharide side chain of apolipoprotein C-III from human plasma very low density lipoprotein. Biochim. Biophys. Acta. 541: 234-240.

9. Bar-On, H., P. S. Roheim, and H. A. Eder. 1976. Serum lipoproteins and apolipoproteins in rats with streptozotocin-induced diabetes. J. Clin. Invest. 57: 714-721.

10. Witztum, J. L., and G. Schonfeld. 1978. Carbohydrate diet induced changes in very low density lipoprotein composition and structure. Diabetes. 27: 1215-1229.

11. Falko, J. M., G. Schonfeld, J. L., Witztum, J. B. Kolar, and P. Salmon. 1980. Effects of short-term carbohydrate, fat-free diet on plasma levels of apo C-II and apo C-III and on the apo-C subspecies in human plasma lipoproteins. Metab. Clin. Exp. 29: 654-661.

12. Stocks, J., G. Holdsworth, and D. J. Galton. 1979. Hypertriglyceridaemia associated with an abnormal triglyceride-rich lipoprotein carrying excess apolipoprotein C-III-2. Lancet. II: 667-671.

13. Hinton, R. H., Y. Al-Tamer, A. Mallinson, and V. Marks. 1974. The use of density gradient centrifugation for the separation of serum lipoproteins. Clin. Chim. Acta. 53: 355-360.

14. Kane, J. P. 1973. A rapid electrophoretic technique for identification of subunit species of apoproteins in serum lipoproteins. Anal. Biochem. 53: 350-364.

15. Scanu, A. M., and C. Edelstein. 1971. Solubility in aqueous solutions of ethanol of the small molecular weight peptides of the serum very low density and high density lipoprotein. Anal. Biochem. 44: 576.

16. Stocks, J., G. Holdsworth, P. Dodson, and D. J. Galton. 1981. An abnormal triglyceride-rich lipoprotein carrying excess apolipoprotein C-II. Atherosclerosis. 38: 1-9.

17. Cramp, D. C., and G. Robertson. 1968. The fluorometric assay of triglyceride by a semiautomated method. Anal. Biochem. 25: 246-251.

18. Holdsworth, G., K. G. Taylor, and D. J. Galton. 1979. Lipoprotein lipase activity in human adipose tissue during induced hypertriglyceridaemia. Atherosclerosis. 33: 253-258.

19. Belfrage, P., and M. Vaughan. 1969. A simple liquid partition system for isolation of labelled oleic acid from mixtures of glycerides. J. Lipid Res. 10: 341-344.

20. Shore, V. G., and B. Shore. 1973. Heterogeneity of human plasma very low density lipoproteins. Separation of species differing in protein components. Biochemistry. 12: 502-507.

21. Carlson, L. A., and D. Ballantyne. 1976. Changing relative proportions of apolipoproteins C-II and C-III of very low density lipoproteins in hypertriglyceridaemia. Atherosclerosis. 23: 563-568.

22. Nestruck, A. C., and D. Rubinstein. 1976. The synthesis of apoproteins of very low density lipoproteins isolated from the Golgi apparatus of rat liver. Can. J. Biochem. 54: 617-628.

23. Martinez, J., J. E. Palascak, and D. Kwasniak. 1978. Abnormal sialic content of the dysfibrinogenemia associated with liver disease. J. Clin. Invest. 61: 535-538. 